\title{
Intraoperative failure of a Fluotec Mark II vapourizer
}

A case report describing the failure of a Fluotec Mark II vapourizer to deliver the indicated anaesthetic concentration during surgery is presented. The failure was caused by a broken internal circlip which resulted in most of the fresh gas flow bypassing the vapourizer. The inspired halothane concentration was reduced to 0.1 per cent, irrespective of the vapourizer dial setting. This type of vapourizer failure may be identified by the unusually loose dial on the Mark II vapourizer. The complications resulting from a light level of anaesthesia include awareness, systolic and diastolic hypertension, movement, and their sequelae.

\section{Key words}

EQUIPMENT: vapourizer failure; COMPLICATIONS: awareness.

The intraoperative failure of a vapourizer to deliver the indicated anaesthetic concentration may result in serious consequences. We describe the failure of a commonly-used vapourizer (Fluotec Mark II) to deliver the indicated anaesthetic concentration during surgery and discuss the potential complications which may result.

\section{Report of a case}

A 17 -year-old ( $55 \mathrm{~kg}$ ) female, ASA physical status II, was scheduled for out-patient dental surgery under general anaesthesia. Her functional enquiry was unremarkable with the exception of a history of asthma during childhood. Current medications consisted of Intal ${ }^{R}$ (cromoglycate) capsules, Beclovent ${ }^{R}$

From the Department of Anaesthesia, The Hospital for Sick Children, Toronto, Ontario.

Address correspondence to: Dr. J. Lerman, Dept. of Anaesthesia, The Hospital for Sick Children, 555 University Avenue, Toronto, Ont. M5G 1 X8. (beclomethasone), and Beconase $\mathrm{R}^{\mathrm{R}}$ (beclomethasone).

A thorough check of the anaesthetic machine, Bain circuit, and anaesthetic equipment was completed preoperatively. The vapourizer was filled with halothane and the odour of halothane was detectable in the fresh gas.

The patient was fasting and unpremedicated. After an electrocardiogram, blood pressure cuff and precordial stethoscope were placed in position, an intravenous catheter was inserted. Three minutes after intravenous administration of $0.5 \mathrm{mg}$ pancuronium, general anaesthesia was induced with $5 \mathrm{mg} \cdot \mathrm{kg}^{-1}$ thiopentone, and $1.5 \mathrm{mg} \cdot \mathrm{kg}^{-1}$ succinylcholine. The lungs were ventilated with 100 per cent oxygen by mask, and the trachea was intubated. Initially, the lungs were ventilated manually with a gas mixture of one per cent halothane (dial setting) in 70 per cent $\mathrm{N}_{2} \mathrm{O}$ and 30 per cent $\mathrm{O}_{2}$, at a total fresh gas flow of $101 \cdot \mathrm{min}^{-1}$. Ventilation was equal in both lungs. During surgery, ventilation was spontaneous with a gas mixture of 1.5 per cent halothane (dial setting) in 70 per cent $\mathrm{N}_{2} \mathrm{O}$ and 30 per cent $\mathrm{O}_{2}$. Heart rate and blood pressure remained stable for the first 30 minutes of surgery after which time sinus tachycardia (130 bpm), systolic hypertension (140 torr), and an irregular pattern of respiration were noted. Skin colour and axillary temperature were normal, and ventilation remained equal in both lungs. The anaesthetic machine was checked again and no faults were detected. The odour of halothane was detected in the fresh gas, but because of the circulatory and respiratory changes, it was concluded that an inadequate depth of anaesthesia was present. The inspired concentration of halothane was increased to 2.5 per cent (dial setting). Despite increasing the concentration of halothane, the patient's respiratory pattern became more irregular, as breathholding and swallowing were noted. Ventilation was controlled manually as surgery neared completion. At the completion of surgery, the patient 


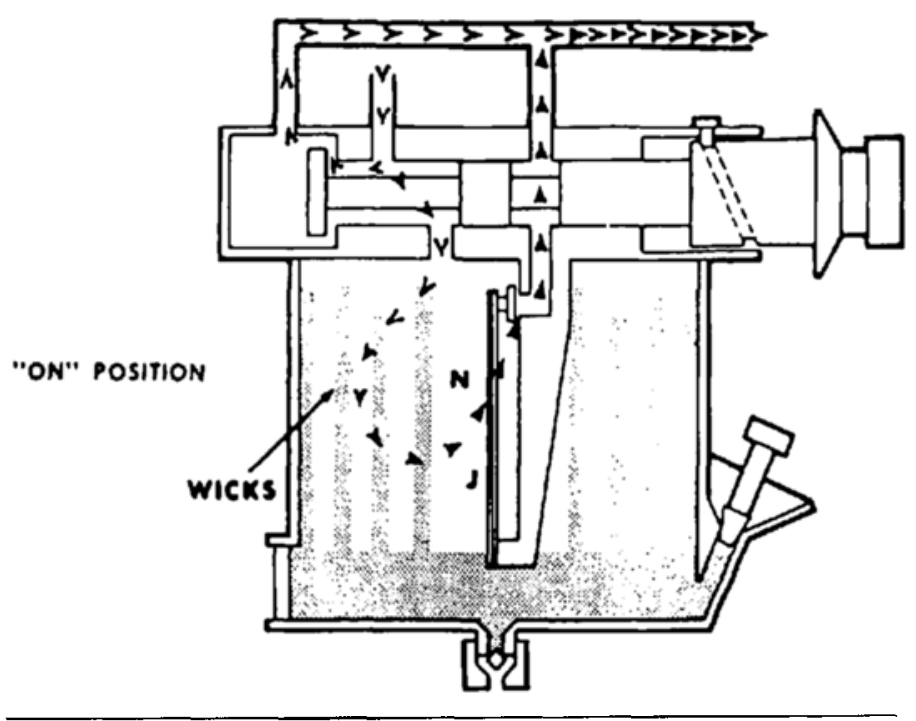

FIGURE I Fluotec Mark II vapourizer. A cross-sectional view of the vapourizer in the on-position with the fresh gas flow indicated by the amows.

coughed and gagged vigorously when her pharynx was suctioned. Within 30 seconds of discontinuing the halothane and nitrous oxide, the patient was fully awake and extubated. There were no sequelae.

\section{Discussion}

This patient was the third in the morning operating room list, after two uneventful dental procedures in which the same anaesthetic machine and vapourizer had been used. We were concerned that a fault existed within the anaesthetic machine or the vapourizer.

When the Fluotec Mark II vapourizer was examined closely, the dial seemed unusually loose when it was pulled out and tumed. Although this was noted during the surgery, the loose dial was attributed to a well-serviced vapourizer. Moreover, the odour of halothane was only faintly detectable in the fresh gas at all dial settings up to five per cent. Because the vapourizer may have been at fault, it was removed to investigate the problem.

In the laboratory, the concentration of halothane delivered by the vapourizer was measured with a Narkotest analyzer., ${ }^{1,2}$ The inspired halothane concentration in a $61 \cdot \mathrm{min}^{-1}$ fresh gas flow of oxygen was 0.1 per cent at all dial settings. Because this vapourizer was due for an annual maintenance check in two months, the vapourizer was sent to the local service company for both a detailed investigation of the defect and an annual maintenance check.

To understand the defect present in this vapourizer, we will refer to Figures 1 and 2. Figure 1 is a crosssectional view of a Fluotec Mark II vapourizer. Figure 2 is a close-up of the internal end of the spindle from the Fluotec Mark II vapourizer shown in Figure 1. Normally, the T-shaped splitting valve (position F) shown in Figure 2 fits inside the main spindle $S$, and is held in place by spring II. Spring I, which is stronger than spring 11 , sits on the casing at one end and abuts on a circlip (a C-shaped ring) at the other end. The circlip rests in a groove on the main spindle (under its own tension) and separates Spring I from the splitting valve. When the dial on the vapourizer is pulled out and turned, the main spindle moves to the right in Figure 2, putting spring I under tension. This movement reduces the size of port $P$, and directs the fresh gas around the main spindle and into the vapourizer through port C. In this case, the circlip holding spring I broke. Spring I was then free to disengage the splitting valve from the main spindle and move the valve back from position $F$ to position $E$. This fully opened port $P$, and allowed most of the fresh gas to bypass the vapourizer, although a small fraction of 


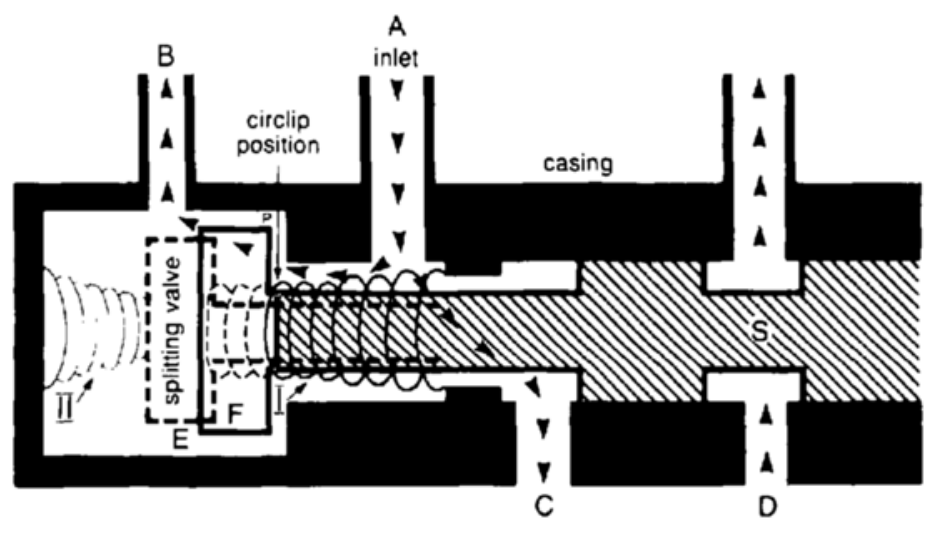

FIGURE 2 Close-up of the vapourizer spindle. Internal end of the vapourizer spindle indicating the position of springs I and II. Srring I is shown in both the normal (solid) and disconnected (dashed) positions. The direction of fresh gas flow is indicated by the arrows.

the fresh gas entered the vapourizer through port $\mathrm{C}$. The inspired concentration of halothane (the combined bypass gas (B) and the gas passing through the vapourizer (D)) was approximately 0.1 per cent. Therefore, when the circlip broke, the inspired concentration of halothane decreased to a very low concentration ( 0.1 per cent) and remained at that low concentration at all dial settings.

Although this type of vapourizer failure does not result in dangerously high anaesthetic concentrations as described in a previous model, ${ }^{3}$ it does result in unexpectedly low concentrations of halothane which could result in serious consequences if: (1) awareness occurred, particularly in a paralyzed patient, (2) systemic hypertension and tachycardia precipitated arrhythmias, myocardial ischaemia or a cerebrovascular accident, or (3) the patient moved and complicated the surgery (i.e., open eye surgery). The distributor* has informed us that in his experience, such a vapourizer failure is rare, particularly during anaesthesia and surgery. A search of the literature failed to identify any reports of such an intraoperative vapourizer failure. However, as this case report indicates, vapourizer failure may occur even during anaesthesia and surgery.

Failure of a vapourizer to deliver the dialed anaesthetic concentration must be included in the differential diagnosis of an unexpected tachycardia

*Fraser Sweatman, Toronto, personal communication and suspected light level of anaesthesia. The only clue to this type of vapourizer failure may be the unusual ease with which the dial on the Fluotec Mark II vapourizer turns.

\section{References}

1 Scurr C, Eeldman S. Scientific foundations of anaesthesia. Philadelphia, FA Davis Company, 1982, pp. 87-8.

2 Lowe HJ, Hagler KJ. Clinical and laboratory evaluation of an expired anesthetic gas monitor (Narkotest). Anesthesiology 1971; 34: 378-82.

3 Baxter VT. Cardiac arrest following administration of a high concentration of halothane vapour. $\mathrm{Br} \mathrm{J}$ Anaesth 1960; 32: 171-80.

\section{Résumé}

On rapporte un incident technigue oì un vaporisateur Fluotec Mark II fournissait une concentration de vapeur moindre que celle affichée. On a trouvé que la presque totalité des gaz frais passait tout droit sans entrer dans le vaporisateur à cause de la rupture d'un anneau d'étanchéité interne. La concentration produite était réduite à 0.1 pour cent indépendamment du réglage au cadran. On peut soupçonner ce type de bris sur le vaporisateur Mark II lorsque le cadran de réglage est anormalement mobile. Les conséquences d'un tel incident sont celles de l'anesthésie trop légère soit: retour de conscience, hypertension systolique et diastolique et mouvements du patient. 